\title{
How Does the Help Desk Quality Improve Customer Satisfaction?
}

\author{
By Ivan Pogarcic* \\ Sanja Raspor Jankovic ${ }^{\dagger}$ \\ Rusudan Seturidze $e^{t}$
}

\begin{abstract}
Internet, virtual environments, and all the other modern forms of communication are a reality of modern man. Various forms of service with which we try to better the quality of daily life are becoming more sophisticated. Their consumption is often a process that requires a precise definition of all of the activities of which it is composed. IT support is just part of that process. The implementation of these activities requires a precise definition of the behavior of all participants. It is necessary to specify the legal rights and obligations of service providers and consumers of these services. Usually such services are agreed upon through the signing of contracts based on the level of services. Actors of such processes necessarily need knowledge, ability, and skills to use such services. Each and every service is a process that covers common behavior and can be automated or displayed as a computer program. The problems are the exceptions in such behavior that cannot be supported by your computer promptly. The service provider to such a situation cannot answer promptly, which becomes a problem for implementation services. The most common forms of support in these situations are known as Help Desk support. The service provider is in such situations forced to provide live-telephone communication with consumers. The problem with such communication is a discrepancy in the competence of participants required for the implementation of services. Providers of desktop support very often employ staff that is usually only accustomed to solving a certain number of problem situations. Training takes place most likely on the basis of empirical reasoning based on the collected number of cases that can be considered stereotypical behavior. This paper presents research that aims to point out the pros and cons of Help Desk support. Defining stereotypes is strictly related to the type and category of service. At the same time, it should be borne in mind that a service is a process defined by the needs of users and depends to a large extent on the users themselves and their characteristics. The data collected for purpose of this research are the basis of an attempt to define stereotypes of services that must be supported by Help Desk activities. This refers as much to the stereotype of users as it does to the stereotype of services offered through the Help Desk.
\end{abstract}

Keywords: communication, Help Desk, service, Service Level Agreement, stereotype behavior.

\section{Introduction}

Computers have entered daily life with a lot of noise, but with effects that at the very least require careful consideration and evaluation. There are many reasons for this, and each deserves serious consideration. However, the list of properties, both bad and good, is not static, and will not be finalized at any time. Approach to the assessment and evaluation of the overall effects depends on the viewpoint from which the entire phenomenon of the computerization of

\footnotetext{
* Assistant Professor, Polytechnic of Rijeka, Croatia.

${ }^{\dagger}$ Senior Lecturer, Polytechnic of Rijeka, Croatia.

* Assistant Professor, Department of Economics and Business, Tbilisi State University, Georgia.
} 
society is observed. Of course, the whole phenomenon can also be viewed from a pragmatic point of view. When properties of informatization and information society as a whole are being considered in such a manner, apart from the point of view/starting point, it is important to know who assesses and evaluates the entire phenomenon. Generally, in such relationships the generic type of userservice provider communication relationship is established. For the purposes of this discussion, it is necessary to take a precise stance towards the concept of services as a stereotype or generic form of non-computer or other type of information activities realized as a necessity of users.

Information systems are essentially related to corresponding business manufacturing or service systems. Only as such a pair can they be possible, but it does not necessarily exist and work. For such conditions, it is essential to have a third component - the user. Where there is no user, there is no real system. The physical frameworks of such systems include not only the part that is responsible for the purely informational side, but also the business functions that are sometimes essential for existential and life questions. Today, even whole countries are proclaimed as eStates. Consequently, this means that activities such as management, education, health, municipal services, etc., appear in their eFormat eHealth and the like.

Such frameworks usually incorporate special separate activities in which actual users sometimes find themselves in a position that can be tentatively called the eUser. When their needs are set into eFrameworks, we usually start talking about virtual frameworks. It is then important to keep in mind that the needs of users are anything but virtual. If it is possible to make a division into the real/ physical activities that accomplish the service and the accompanying information activities necessary for the realization of these, a second accompanying problem may arise. It is the ability of users to safely and adequately consume necessary services. Very often these activities are previously agreed upon and prepared according to the corresponding instructions. However, to follow these instructions means to make mistakes in that order. Information systems that support such activities must have a part/service that can amortize these types of problems and errors. Usually, such a part or service is called a Help Desk or service for communication with users. Accordingly, the Help Desk is part of the formal business or part of the information system. The specific feature of this part of the system is determined by its primary function - providing interfaces between users and service providers.

The aim of this paper is to consider this function from the point of its appearance in terms of quality and quantity. Because the quality of its appearance is determined by the user or consumer, it is necessary to detect the attitude and behavior of users. This is difficult to do at an abstract or generic level. The reason for this is the determinants of quality. To this end, certain specific concretization and simplification was necessary. The paper thus deliberately or inadvertently makes omissions or neglects certain facts. In such circumstances, these facts are just mentioned explicitly for creating an overall picture of the phenomenon of the Help Desk. 
In addition to defining the concepts, the paper also includes an overview of literature related to the phenomenon of the Help Desk; a description of the preparation and methods of research; the selection of initial attitudes and opinions, or a kind of a hypothesis; results processing; an interpretation of the results; and a conclusion with a proposal for further research.

User satisfaction with the Help Desk is primarily due to the quality of service delivery. However, the user is an active participant in the realization of this service. When a service is realized through information processes within the Help Desk, it is assumed that the user has the appropriate knowledge and skills to activate and realize the service as a process. Such a presumption has the effect of conditioning the user's satisfaction and abilities. Thus, from the customer's point of view, the quality score of the Help Desk has both an objective and a subjective side. The research attempted to determine the more objective framework for assessing and evaluating the Help Desk phenomenon at a generic level, taking into account the objectivity of respondents' responses.

\section{The Framework - Need for a Help Desk as a Communication Element}

Each operating system includes a set of activities and processes that help to realize its function. The nature and objectives of that realization are not important and can be observed generally on an abstract level. However, each activity and every business process is necessarily accompanied by a corresponding information process. This symbiosis between business and information functions is necessary because individually these two processes could not exist. Therefore, separate observation of one can only help in understanding the other.

In this way, the definition of an information system is always put in a pragmatic context. In general, the definition of an information system is most often linked to the pragmatic aspects of securing the information and data necessary for business and business management through the adoption of appropriate management decisions. It is this very aspect that is important for this study.

We can form a working definition of the information system and its importance for the business system, provided that the definition attaches to the most important element of this system, which is the user. From a philosophical and logical point of view, a system without a user as could possibly exist as a phenomenon, but its meaning and purpose would be undefined. The system becomes a reality only when it has an active user.

Taking into account the above facts, we can accept the following working definitions for the system in general and the information system specifically:

- A system is a collection of interconnected elements that when coupled realize a specific function;

- An information system is a system that is used to collect, process, store and disseminate information and data to users, which are needed to get certain benefits and services. 
In theory, but also in practice, the development of information systems, especially computer software, has called the user by different names. The name has been changed and harmonized with the needs of standardization and unification of certain development procedures, methods, techniques and technologies. Though the name has been changed, the role and position of the user have not. Beginning in the early forms of monolithic software (Figure 1) to the modern cloud architecture (multi tier, Figure 2), throughout literature we can find everything from users, clients, and actors in the Service-Oriented Architecture (SOA) (Erl, 2005), or cloud computing architecture of information systems (Erl, 2013). The effort to standardize and design tools, such as the UML, can easily be spotted. Although boldness is necessary to call something like that a language, it is this very fact that is of particular importance for the conducted study. It is necessary to mention that every language, among other things, is first of all a means of communication. Other features, such as semantics, syntax or graphemes, which the language must necessarily possess, are important but in this case less important. ${ }^{1}$

Figure 1. Monolithic Architecture

\section{MONOLITHIC ARCHITECTURE}

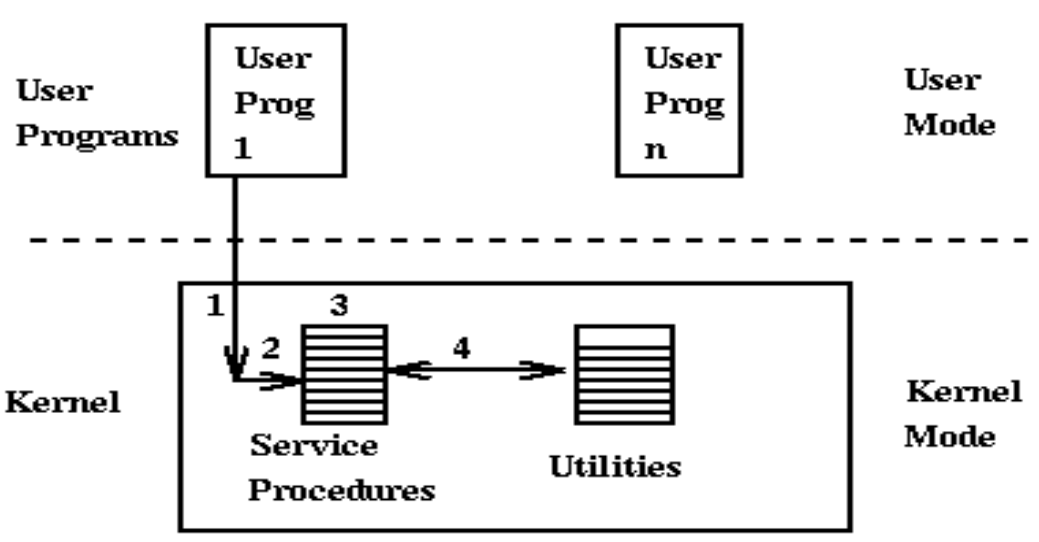

1. System call (User->Kernel Mode)

2. Check parameters

3. Call service routine

4. Service Routine call utilities

Reschedule/Return to user

The main subject of this research is in fact communication as a means for the realization of services that users expect from a system in which they take part, or if they were for any reason confronted with a system from their environment.

From this aspect, communication is seen as a pragmatic relationship of users and systems through which users, let them be so called (or even actors), and are achieving their objectives, activities, or services.

\footnotetext{
${ }^{1}$ Retrieved from goo.gl/DgSB1S. Accessed: April 9, 2017.
} 
In the following text, this relationship user-system will usually be viewed in terms of modern technical possibilities and different ICT givens. However, it is not necessary that this relationship be strictly linked to ICT or even more closely to computers and computing environments. Such an attitude will be supported by assuming the use of ICT and computer-supported activities, as well as the existence of appropriate software solutions. Of course, such relationships can be considered only under the assumption that there are possibilities and equipment necessary for communication in such conditions.

Finally, it is necessary to define communication from both pragmatic and technical aspects for the needs of a clear and unequivocal user-system relationship (Figure 3). It is particularly important to determine the advantages and possible disadvantages of such a relationship, which may cause dysfunction within the system. Of special interest is the Help Desk as the physical and functional part of communications and systems in general.

Figure 2. Multi-Tier Architecture

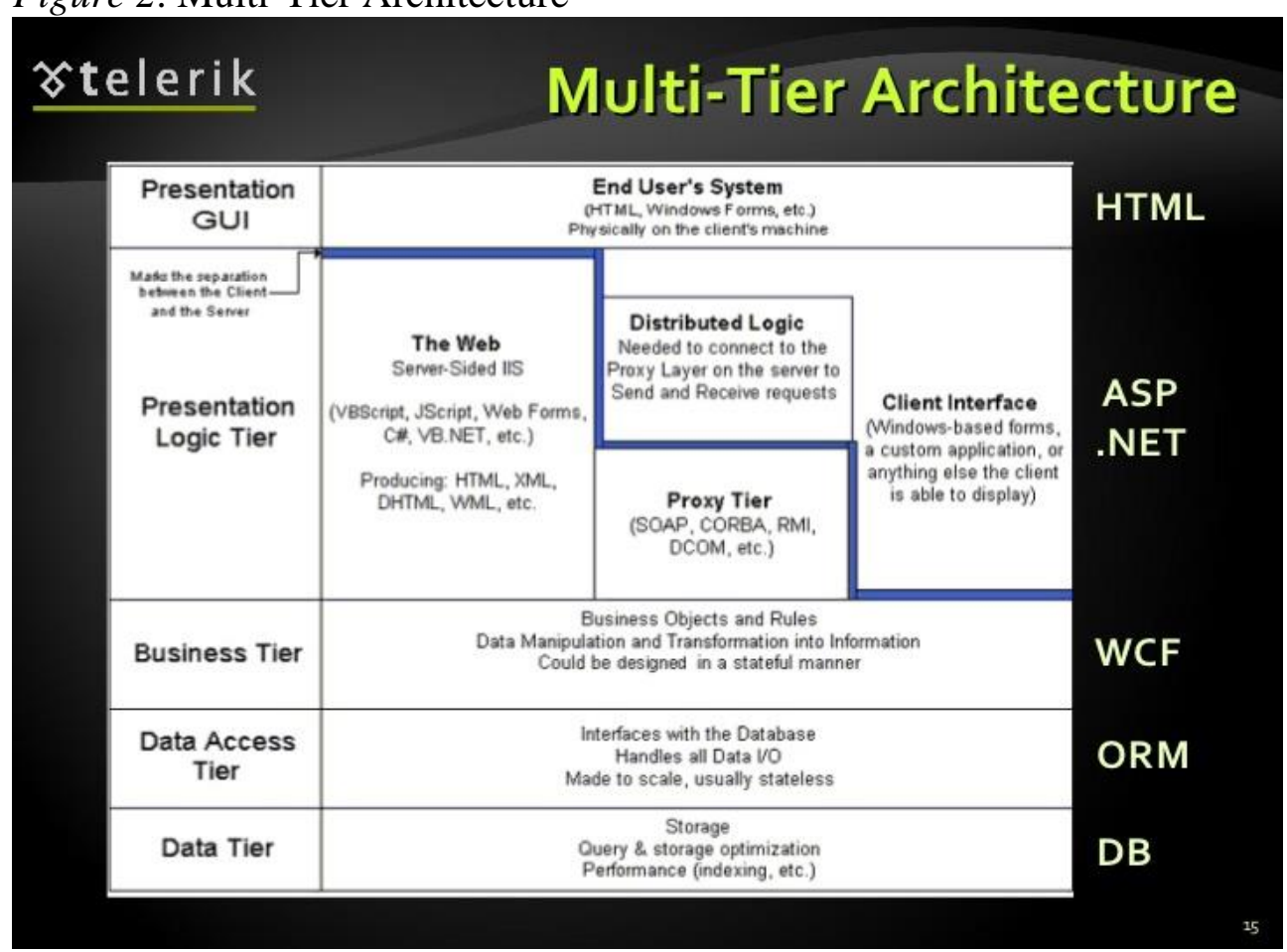

Source: goo.gl/UkJWcu, accessed: April 9, 2017.

\section{Help Desk and Its Framework}

The central subject of the research is user satisfaction with the services provided and attempts to look at possible ways to improve these services. The quality and character are observed in terms of users and their satisfaction with the services that are realized or regulated through the activities and communicated through them. 
Figure 3 is a generic display of communication at the defined level given by (Shannon $\&$ Weaver, 1963) i.e. it can be viewed from a purely mechanical/ mechanistic point of view. In this specific case, the environment in which the service is realized is usually more sophisticated and goes beyond the presented generic form.

Figure 3. Communication

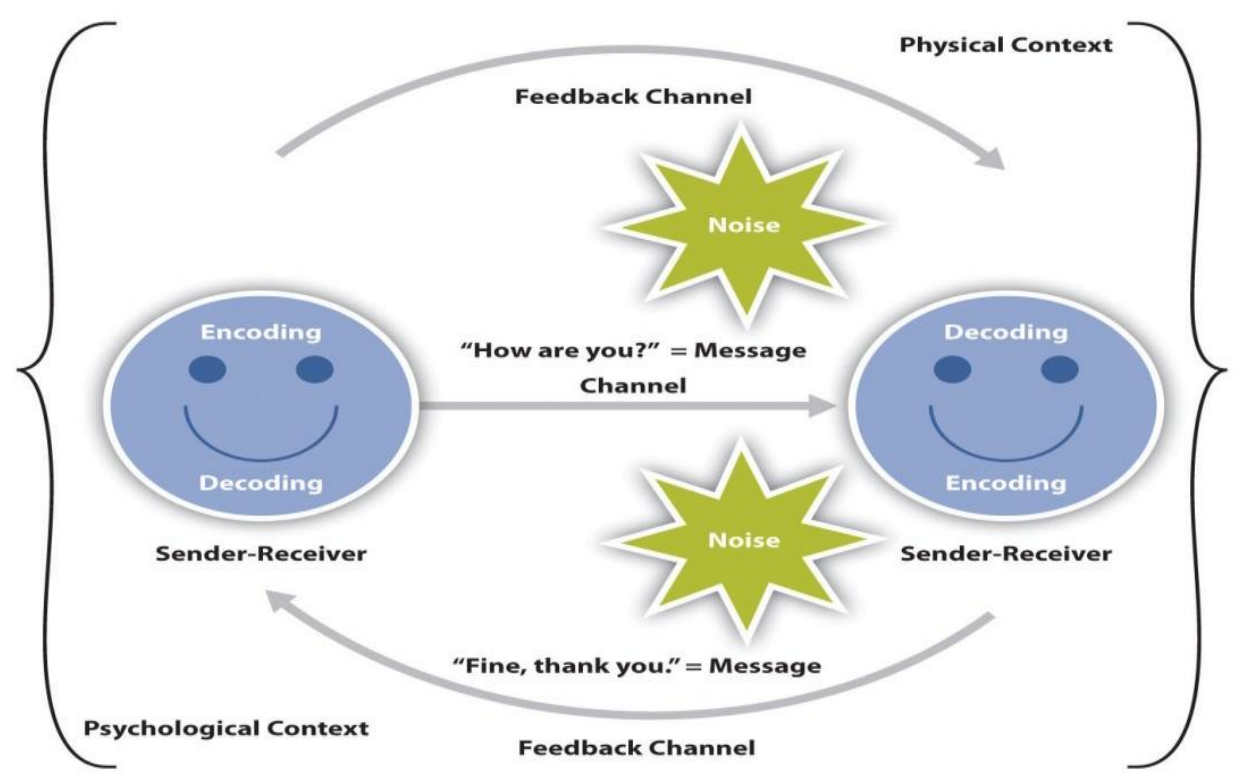

Source: goo.gl/ExaD8j, accessed: April 9, 2017.

The ubiquity of computers and various ICT devices have created a consumerist environment in which users are provided with different options of course, under the unspoken assumption that such infrastructure opportunities are at the disposal of users. Regardless of the sense of global coverage and networking, this is not the case. Rather, the trend of development and coverage in certain areas and the development of network capabilities and availability leave the possibility of a general hypothesis and conclusion. Trends are extensive and unstoppable. In other words, everything a computer can replace a man in doing can be and should be designed as a service that comes from the environment of a real system and its information versions.

Therefore, this issue can be accessed from various aspects. The presence and need for computers occur in all human activities, especially those that can in any way be automated and translated into a computer-formatted service.

Each of these terms is a communication of the user with another user or users through ICT. In such circumstances, we talk about eCitizens, eGovernment, eAdministration, eLearning, etc. Some countries/states are implementing these plans and activities at enviable speeds and ambitiously endeavor to achieve the degree of an eState. Of course, only within the boundaries of the society/state where the infrastructure allows the integrity of general eAccess and general eCapabilities. Everything else can be considered an eTransient state. 
For example, eGovernment (short for electronic government) (OECD, n.d., p. 6) is the use of electronic communications devices, computers and the Internet to provide public services to citizens and other persons in a country or region. According to (Jeong, 2007), the term consists of the digital interactions between a citizen and his or her government $(\mathrm{C} 2 \mathrm{G})$, between multiple government agencies $(\mathrm{G} 2 \mathrm{G})$, between the government and its citizens $(\mathrm{G} 2 \mathrm{C})$, between the government and its employees (G2E), and between government and businesses or commerce (G2B). E-government delivery models can be broken down into the following two categories: The interaction which consists of citizens communicating with all levels of government (city, state/province, national, and international), facilitating citizen involvement in governance using information and communication technology (ICT) such as computers and websites, and business process re-engineering (BPR) (Jeong, 2007) .

The first division emphasizes the type of communication and actors appearing in this communication, either individually or as a group. The second division is made with respect to certain hierarchies regarding the organization of communities.

From the standpoint of computer science and information science, it is necessary to consider the structure and organization of such communication. Exchange of information occurs in the communication channel at the ends of which is the user and the information or service provider. Within the eFrameworks exchange, the information/service is mediated by specific software. This software is necessarily in the jurisdiction of its author or other authorized persons/actors. The professional and expert responsibility of that person is implied if functional communication with the user is expected. These properties of authors are not only needed but also necessary. In the case of software solutions, knowledge and skills in the field of programming and design of computer applications are implied.

On the other side is the user (eCitizen) whose knowledge, skills and abilities are assumed, so it may be questionable. When defining services for such frameworks, assumptions of this kind are necessary. However, the presumption is linked to a certain level of probability of realization. Furthermore, the realization itself does not guarantee quality of service and avoidance of mistakes, or even worse conflict situations. The hardest thing of all is that such exceptions, errors, and conflicts require prompt resolution and further reduce the quality of service and user confidence in the system in general.

\section{Help Desk as a Realization - Overview of Literature}

Through an overview of the current literature, it is possible to determine the relevant basic concepts based on comparing the attitudes of the respective authors. In addition to highlighting a basic definition of the Help Desk in the following review, it is easy to see that most authors are turning to recommendations for specific organization and customer support. 
Therefore, in this part, the specifics are neglected because they would lead to too much broadness without significant yield, except for the purely statistical yield of collateral significance. This is evident from the following examples.

(Beisse, 2014), along with a systematic overview of the development of computers, gives users' possibilities and the necessary technological framework for communication with the Help Desk staff. A similar overview and structure can be found in (Czegel, 1998), which especially emphasizes the importance of focusing on business processes and activities. The book by (James, 2016) is specifically limited in its definition to the IT area. The authors define the Help Desk as a resource business system whose function is to provide information and necessary support to the end user. Similarly organized is the book by (Bruton, 2002), who through a number of case studies approaches the issues with an emphasis on user support as an IT function of the information system. Especially well developed are the types and forms of support. With regard to the quality of support and end user satisfaction, it is good to study the book by (Mohr, 2003) in which the author gives a quality proposal for the revision of the Help Desk and a convenient Maturity Model.

In operational terms, there are plenty of high-quality materials that can be used as instructions for the organization of a Help Desk as part of a business/ information system and the realization of operational activities. Among all others, (Novell@, 2009) deserves special recommendation and a brief instruction (Help Desk Service, n.d.), as well as Help Desk Best Practices (n.d.) examples in compliance with recent architectures of information systems such as Guide to SaaS Help Desk (2011). The Internet offers a wide range of different views, notes and similar materials with different levels of expertise. A good portion of the material is made for marketing promotions of software applications designed for specific needs. Some of them are made with the intention to be a generic format that can be tailored to a specific purpose (Rumburg \& Zbikowski, n.d.).

\section{How Help Desk is Truly User - Centric}

Already from the basic definition of the Help Desk, the emphasis on the position of users and their needs is quite visible, i.e. support needed to solve customer problems. It is not so important for the users to know the origin of the Help Desk, nor the manner of its functioning. This shows the implementation of an attitude proclaimed by the philosophy of an object-oriented approach in the development of information systems. (Eckel, 2006) states, "It does not matter how it works, the important thing is what it does and that it works in a satisfactory manner". However, the technology here must be viewed from two angles.

The first view is a way to help the user to solve problems arising from the use of other technology. This paper is not a detailed elaboration of user profiles, nor a more detailed expert analysis of the communication channel through which users realize their needs in a system. The assumptions are that all the above exists as a reality and that, within these frameworks, problems can develop in the domain of realization of customer needs. A prerequisite for these relationships is sufficiently 
user experience in the use of technology, the user's exposure to technology in the realization of their needs and the possible necessity for the use of technology at the same time. These facts are sufficient for Help Desk user profiling. Users should be aware of possible indirect problems that are beyond their control and the control of the direct service provider. These are problems related to the network, security problems, or infrastructure.

The second view, there are conditions related to the normal functioning of the Help Desk from the organizational domain and service management domain. For the user of services it is irrelevant how the Help Desk service is organized and how it is structured; how the database is organized; and the way in which performance is measured. While it is important that the service possess certain certificates and adheres to certain standards, it is not necessary for the user to know this.

The problem, or the incident situation, is the driver of communication. Normally communication begins with the initial contact, user authentication on the one hand and logging in, screening calls, and prioritization if necessary. Users experience all these activities personally, and they are important for them and for the service provider (Figure 4, example is narrowly specific but a good illustration).

Figure 4. The Intelligent Help Desk: Supporting Peer-Help in a University Course

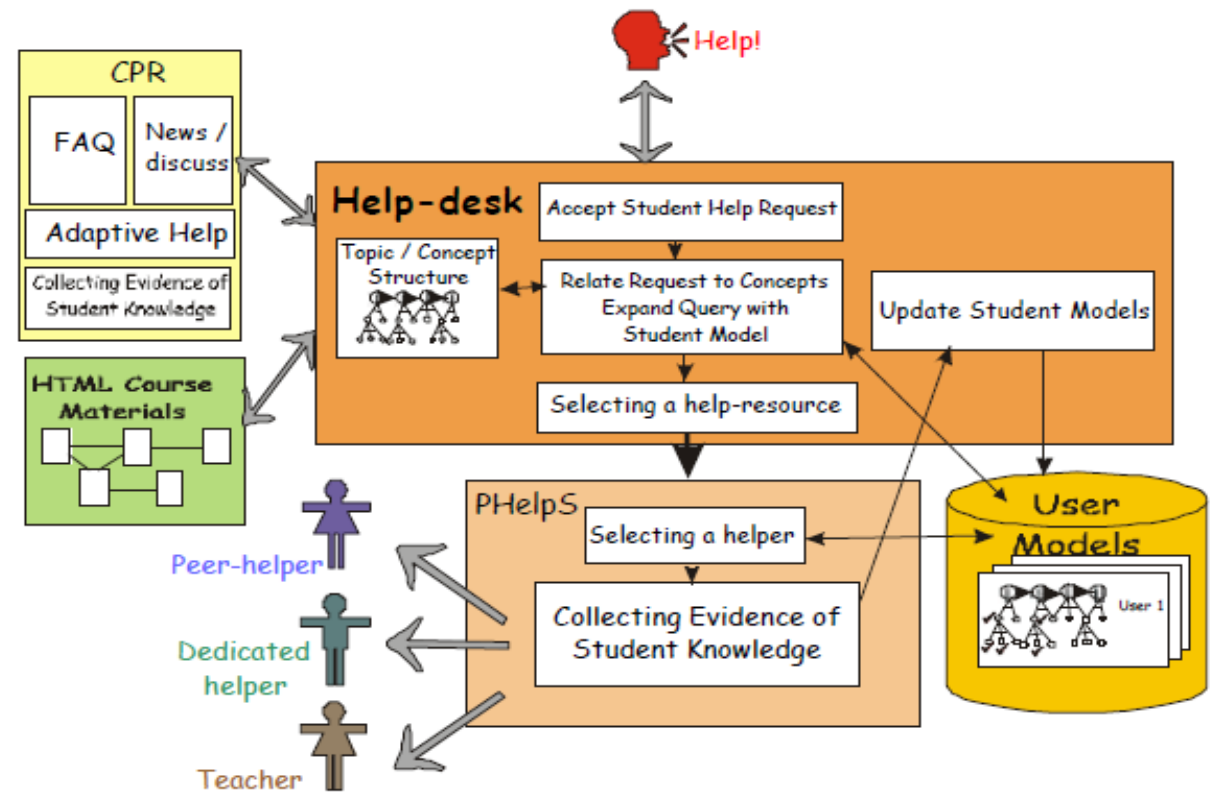

Source: goo.gl/UkJWcu, accessed: April9, 2017.

The process of service itself from the provider's point of view includes a number of activities from receipt of the request and its interpretation to validation and formulation of a response. This process always has an emotional component that can be reason for even greater incident, now a communication one. This part is also implied, but is dependent on several factors. The methods of communication and level of knowledge of Help Desk employees are paramount. 
The style of communication, such as listening carefully and taking the users into account, is prerequisite for quality services.

Solving the incident is entirely in the domain of the service provider, but the resolution and quality solutions are as important for the user as for the service provider.

Today, the vast majority of Help Desk services are uploaded on the Internet as Web services. For this purpose, a range of technologies, techniques, and methods are applied in this environment. Thus, services of the Self-Service support type are possible, which in turn have their own specific advantages and disadvantages. It is necessary in terms of user expectations to emphasize another division of services and support. These are Real-Time Assisted Support and Delayed Assisted Support. In the Web environment, much iteration are possible, such as Live Chat, Remote Control Programs, E-mail and Discussion Forums. Service realization management usually assumes the existence of an appropriate Service Level Agreement (SLA), a mutually signed agreement, and a database of all types of incidents, customer satisfaction, and characteristics of certain problems maintained by the Help Desk (Wiese, 2017).

\section{Survey and Objective}

The subject of this research is to determine the profile and attitudes toward the associated Help Desk services. Specifically, we attempt to determine the quality level of individual services and customer satisfaction with the services received. For this purpose, an online survey was prepared. The survey was anonymous. There were neither conditions nor a targeted population. It was only assumed that the respondents consume or have consumed services of any type from a Help Desk in one of the offered areas. Limitations and guidance according to the population included an assumption of the existence of infrastructure possibilities, certain types of SLAs, and appropriate skills of those surveyed in the use of ICT technology.

The survey was made up of two parts with a total of 17 questions. The first part, four questions, was related to the determination of demographic data including gender, age, level of education, and area of activity. The second part, 13 questions, included questions related to the offered areas in which the need for organized support can occur in any way that can be called a Help Desk.

Since a prerequisite was the existence of these minimum conditions, the survey was limited to user needs for services and support in service areas that could be called communal. Thus, possible answers were related to the demographic question "What best describes your area of activity?". With this question, it is possible to carry out subsequent stratification of the population and determine certain patterns.

The fifth question states "Do you have in private life some needs or obligations under organizations in these areas?" and provides feedback on the use of Help Desk services in seven different areas. The question insisted on a reply that indicates such needs but in terms of privacy of respondents. The next 
question "Do you have in professional life some needs or obligations to organizations in mentioned areas?" is a version of the previous question, but focuses on the need in the area of professional activities and needs of a possible workplace. The seventh question reads: "Can you mark some of the activities in which organization offers communication and help in solving problems through institution and activity forms "Help Desk"?" This provides feedback about the existence of Help Desk services in offered organizations. Questions 8-11 are related to the possible need, the frequency of problems and support, the assessment of the level of consumption of services and assessment of satisfaction with the offered support and obtained solution, respectively.

Q8: Did you ever need help in solving the problems in communication and fulfillment of its obligations with these activities?

Q9: Did you use the service and how much these services from Help Desk in organizations with aforementioned activities?

Q10: Can you estimate the percentage level of your use of the service Help Desk of these organizations?

Q11: To what degree are you satisfied (possible) with the service provided?

Answers to Questions 12 and 13 are feedback about the things users were satisfied (Q12: Which you are not satisfied with providing Help Desk assistance?) and unsatisfied (Q13: What you satisfied with providing a Help Desk?) with. In both cases, six attributes were offered to describe dissatisfaction and one option at the discretion of the surveyed. Question 14 (Q14: Help Desk can be organized in various forms and on different places. Which form you prefer?) was used to detect the most common forms of physical realization of the Help Desk service. Question 15 (Q15: Assuming that you have a negative opinion of Help Desk support which of the following you consider that correct?) sought to identify the most common form of user dissatisfaction with realized services. Question 16 (Q16: If you could be in the position of Head of Help Desk services which would your priority list of offered properties of Help Desk agents?) presents the user with a fictitious possibility of influencing the organization of a Help Desk service. Respondents had to rank the offered guidelines of organizations in their sole discretion and provide their own vision of how Help Desk services and characteristics should be organized. Finally Question 17 (Q17: If you think that we left out some, in your opinion important facts, please list them!) was left for free supplement by respondents in the case that, based on their assessment, something was left out of the survey.

\section{Methodology}

Variables in the questionnaire were measured using a nominal scale and a Likert-type scale with anchors "almost never" (as 1) and "very often" (as 5). Data was gathered during a three-week period in January 2017 using the online questionnaire. The link to the questionnaire was distributed via e-mail with 
the request to forward it to other addresses, if possible. The target population was individuals who potentially encountered Help Desk services. Data collection resulted in a sample of 97 questionnaires. In order to address the study objectives, descriptive statistics were performed.

\section{Findings/Results}

Table 1. Demographic Characteristics

\begin{tabular}{|c|c|}
\hline Characteristics & Percentage \\
\hline \multicolumn{2}{|l|}{ Gender } \\
\hline Male & 46.23 \\
\hline Female & 52.83 \\
\hline Without response & 0.94 \\
\hline \multicolumn{2}{|l|}{ Age } \\
\hline Less than 25 & 39.25 \\
\hline $25-29$ & 11.21 \\
\hline $30-34$ & 10.28 \\
\hline $35-39$ & 10.28 \\
\hline $40-49$ & 15.89 \\
\hline $50-59$ & 7.48 \\
\hline 60 and more & 4.67 \\
\hline Without response & 0.93 \\
\hline \multicolumn{2}{|l|}{ Level of Education } \\
\hline Elementary School & 0.00 \\
\hline High school & 13.21 \\
\hline Undergraduate course & 33.02 \\
\hline Graduate study & 33.02 \\
\hline Postgraduate studies & 9.43 \\
\hline Doctoral & 8.49 \\
\hline Other & 2.83 \\
\hline \multicolumn{2}{|l|}{ Area of Activity } \\
\hline Agriculture, hunting and forestry & 0.00 \\
\hline Mining & 0.00 \\
\hline Manufacturing & 1.89 \\
\hline Electricity, gas and water supply & 1.89 \\
\hline Construction & 1.89 \\
\hline Wholesale and retail trade & 0.00 \\
\hline Hotels and restaurants & 9.43 \\
\hline Transport, storage and communication & 0.94 \\
\hline Financial intermediation & 1.89 \\
\hline Real estate, renting and business activities & 0.94 \\
\hline Public administration and defence; compulsory social security & 0.94 \\
\hline Education & 33.02 \\
\hline Health and social care & 2.83 \\
\hline Other community, social and personal service activities & 23.58 \\
\hline Other & 20.75 \\
\hline
\end{tabular}

Source: Authors' estimations. 
The results are presented as follows. Firstly, demographic profile of the respondents was presented. Secondly, the evaluations of Help Desk's activities and support were examined. Detailed descriptive statistics relating to the respondents' profile is presented in Table 1.

As presented in Table 1, female respondents (52.83\%) outnumbered male respondents in the sample. The majority were younger than 25 years of age $(39.25 \%)$ or were in the age group 25 to 39 (31.77\%). Respondents were evenly distributed between two levels of education, namely undergraduate and graduate study. In addition, the sample consists of respondents from twelve different areas of activity. About one-third of them stated education as their main activity area. Next, the results regarding Help Desk activities and support are presented.

Table 2. Private and Professional Life's Needs or Obligations toward Organizations from Different Area of Activity

\begin{tabular}{|l|c|c|}
\hline Area & $\begin{array}{c}\text { Private } \\
\text { life }\end{array}$ & $\begin{array}{c}\text { Professional } \\
\text { life }\end{array}$ \\
\hline Municipal activities (electricity, gas, water, waste ...) & 71.70 & 20.75 \\
\hline Telecommunications (telephone, mobile phone) & 87.74 & 64.15 \\
\hline Internet communications (social networks, email and the like) & 83.02 & 83.96 \\
\hline eBanking or mBanking & 75.47 & 21.70 \\
\hline eShopping & 46.23 & 14.15 \\
\hline Stock Exchange and the eExchange & 13.21 & 3.77 \\
\hline Other & 1.89 & 0.94 \\
\hline
\end{tabular}

Note: Values in Table represent percentages.

Source: Authors' estimations.

According to the results shown in Table 2, respondents in private life mostly interact with organisations under the telecommunications scope of activity (87.74\%), followed by Internet communications (83.02\%) and banking (75.47\%). What is more, slightly more than $70 \%$ interact with organizations focused on municipal activities. On the other hand, in professional life, the dominant interaction takes place with Internet communications $(83.96 \%)$, followed by telecommunications.

Table 3. Activities in Which Organization Offers Communication and Support through "Help Desk" Service

\begin{tabular}{|l|c|}
\hline Activities & Percentage \\
\hline Municipal activities (electricity, gas, water, waste ...) & 23.81 \\
\hline Telecommunications (telephone, mobile phone) & 72.38 \\
\hline Internet communications (social networks, email and the like) & 64.76 \\
\hline eBanking or mBanking & 52.38 \\
\hline eShopping & 22.86 \\
\hline Stock Exchange and the eExchange & 9.52 \\
\hline Other & 1.90 \\
\hline
\end{tabular}

Source: Authors' estimations.

Most of the respondents (72.38\%) stated telecommunications as one of the area in which organizations offer communication and support through Help 
Desk services. This is followed by Internet communications (64.76\%), and eBanking or mBanking activities $(52.38 \%)$ (Table 3$)$.

As noted in Table 4, respondents most frequently use assistance in telecommunications area of activities. The average score of 2.89 indicates that telecommunications assistance is used sometimes. In addition, assistance in Internet communications and eBanking or mBanking is used rarely (mean scores 2.24 and 2.10, respectively).

Table 4. Frequency of Using Assistance in Solving Difficulties in Communication and Executing Obligations according to the Activities

\begin{tabular}{|l|c|c|}
\hline Activities & Average & Std. Dev. \\
\hline Municipal activities (electricity, gas, water, waste ...) & 1.76 & 0.98 \\
\hline Telecommunications (telephone, mobile phone) & 2.89 & 1.12 \\
\hline Internet communications (social networks, email and the like) & 2.24 & 1.06 \\
\hline eBanking or mBanking & 2.10 & 1.01 \\
\hline eShopping & 1.68 & 0.93 \\
\hline Stock Exchange and the eExchange & 1.28 & 0.81 \\
\hline
\end{tabular}

Note: Mean scores range from 1 to 5 , where 1 means almost never and 5 means very often.

Source: Authors' estimations.

Mean scores for the frequency of using Help Desk services range from 1.12 to 2.08. The most frequently used Help Desk services are in telecommunications. The average score of 2.08 indicates that most of the respondents use these services sometimes. Similarly, sometimes Help Desk services in Internet communications and eBanking or mBanking activities are used. Help Desk services in other activities are almost never used (Table 5).

Table 5. Frequency of Using Help Desk Services according to the Activities

\begin{tabular}{|l|c|c|}
\hline Activities & Average & Std. Dev. \\
\hline Municipal activities (electricity, gas, water, waste ...) & 1.32 & 0.63 \\
\hline Telecommunications (telephone, mobile phone) & 2.08 & 0.86 \\
\hline $\begin{array}{l}\text { Internet communications (social networks, email and } \\
\text { the like) }\end{array}$ & 1.78 & 0.79 \\
\hline eBanking or mBanking & 1.62 & 0.68 \\
\hline eShopping & 1.28 & 0.48 \\
\hline Stock Exchange and the eExchange & 1.12 & 0.39 \\
\hline Others & 1.22 & 0.41 \\
\hline
\end{tabular}

Note: mean scores range from 1 to 4 , where 1 means almost never and 4 means very often. Source: Authors' estimations.

Results in Table 6 indicate that most of the respondents (52\%) believe that the level of benefit from using Help Desk services in municipal activities is up to $25 \%$. Similarly, most of the respondents indicated this level of benefit in Internet communications (31\%), eBanking or mBanking (37\%), and Stock exchange or eExchange. These results represent perceptions of very low benefit levels. On the other hand, about one-third of the respondents stated that they got up to $75 \%$ benefit. 
Results in Table 7 show that most of the respondents rate level of satisfaction with Help Desk services as average, meaning that they were neither satisfied nor dissatisfied. Only a minority was very dissatisfied (4\%) or very satisfied (2\%).

Table 6. Benefit Level of Using Help Desk Services

\begin{tabular}{|l|c|c|c|c|}
\hline Activities & $\begin{array}{c}\text { Up to } \\
\mathbf{2 5 \%}\end{array}$ & $\begin{array}{c}\text { Up to } \\
\mathbf{5 0 \%}\end{array}$ & $\begin{array}{c}\text { Up to } \\
\mathbf{7 5 \%}\end{array}$ & $\begin{array}{c}\text { Up to } \\
\mathbf{1 0 0 \%}\end{array}$ \\
\hline Municipal activities (electricity, gas, water, waste ...) & 52 & 29 & 14 & 5 \\
\hline Telecommunications (telephone, mobile phone) & 23 & 32 & 33 & 12 \\
\hline Internet communications (social networks, email and the like) & 31 & 28 & 29 & 12 \\
\hline eBanking or mBanking & 37 & 20 & 22 & 21 \\
\hline Stock Exchange and the eExchange & 62 & 17 & 11 & 10 \\
\hline Others & 64 & 18 & 10 & 8 \\
\hline
\end{tabular}

Note: Values in Table represent percentages.

Source: Authors' estimations.

Table 7. Level of Satisfaction with Help Desk Service

\begin{tabular}{|l|c|}
\hline Level of satisfaction & Percentage \\
\hline Much worse than average & 4.00 \\
\hline Average & 70.00 \\
\hline Better than average & 24.00 \\
\hline Much better than average & 2.00 \\
\hline
\end{tabular}

Source: Authors' estimations.

Most of the respondents $(63.27 \%)$ indicated that they were not satisfied with the speed of the provided service, followed by efficiency $(43.88 \%)$, and expertise $(36.73 \%)$. The least $(3.06 \%)$ were dissatisfied with the quantity of provided service. On the other hand, almost one-third of the respondents stated that they were satisfied with the speed. In addition, nearly $30 \%$ of them were satisfied with the quality and expertise of provided services. The least (14.29\%) were satisfied with effectiveness of Help Desk service (Table 8).

Table 8. Attribute Dissatisfaction and Satisfaction with Provided Help Desk Assistance

\begin{tabular}{|l|c|c|}
\hline Attribute & Dissatisfaction & Satisfaction \\
\hline Speed & 63.27 & 32.65 \\
\hline Quality & 32.65 & 29.59 \\
\hline Quantity & 3.06 & 16.33 \\
\hline Expertise & 36.73 & 29.59 \\
\hline Efficiency & 43.88 & 17.35 \\
\hline Effectiveness & 19.39 & 14.29 \\
\hline Other & 4.08 & 11.22 \\
\hline
\end{tabular}

Note: Values in Table represent percentages.

Source: Authors' estimations.

Almost $35 \%$ of the respondents prefer telephone communication with Help Desk, followed by virtual online and face-to-face communication. The fewest respondents prefer written completely off-line communication when using Help Desk services (Table 9). 
Table 9. Preferred Form of Help Desk Organisation

\begin{tabular}{|l|c|}
\hline Form of Help Desk Organisation & Percentage \\
\hline Physical communication face-to-face & 25.51 \\
\hline Virtual communication - off line electronic mediation & 6.12 \\
\hline Virtual communication - on line electronic mediation & 30.61 \\
\hline Telephone communication & 34.69 \\
\hline Written - complete off-line communication & 3.06 \\
\hline Other & 0.00 \\
\hline
\end{tabular}

Source: Authors' estimations.

According to the results represented in Table 10, most of the respondents believe that in most cases it is not possible to reach the staff who is really responsible for the problem (62.89\%). In addition, slightly more than $45 \%$ stated that there is no continuity in communication. Thus, these results indicate that Help Desk support is not always reliable.

Table 10. Assumptions Regarding Help Desk Support

\begin{tabular}{|l|c|}
\hline Assumptions & Percentage \\
\hline Expertise of Help Desk staff is insufficient to solve the majority of problems & 37.11 \\
\hline Internal relationship of the staff is not transparent & 24.74 \\
\hline $\begin{array}{l}\text { In most of the cases it is not possible to reach staff that is really } \\
\text { responsible for the problem }\end{array}$ & 62.89 \\
\hline The most of the problems is related to the problem of computer program & 32.99 \\
\hline $\begin{array}{l}\text { The eventual problem could not be posted at the appropriate hierarchical } \\
\text { level - the level of real responsibility person }\end{array}$ & 25.77 \\
\hline $\begin{array}{l}\text { When the problem is in need of legal aid, necessary information is not } \\
\text { provided }\end{array}$ & 24.74 \\
\hline $\begin{array}{l}\text { Communication is not entirely transparent (incorrectly legitimizing agent } \\
\text { and the like) }\end{array}$ & 25.77 \\
\hline $\begin{array}{l}\text { Complete discontinuity in communication (getting the same agent is } \\
\text { usually impossible) }\end{array}$ & 45.36 \\
\hline
\end{tabular}

Source: Authors' estimations.

Finally, as noted in Table 11, the most important characteristic of Help Desk agents is professionalism. Namely, most of the respondents placed this characteristic as the most or second most important aspect $(42.53 \%$ and $19.54 \%$, respectively). The third most important characteristic is communicativeness $(16.09 \%)$, followed by speed $(18.82 \%)$ and quality appreciation of customer requirements. Organizational stage and conciseness are characteristics that were rated as the sixth and seventh most important characteristics of Help Desk agents. What is more, respondents highly appreciate eloquence and a sense for teamwork. Thus, the "ideal" Help Desk agent should be first of all professional and skilled, communicative, agile, able to appreciate customer requirements, organized, concise, eloquent, and a team player. 
Table 11. Priority List of Help Desk Agents' Characteristics

\begin{tabular}{|c|c|c|c|c|c|c|c|c|c|c|c|c|}
\hline \multirow[t]{2}{*}{ Characteristics } & \multicolumn{12}{|c|}{ Ranking } \\
\hline & 1 & 2 & 3 & 4 & 5 & 6 & 7 & 8 & 9 & 10 & 11 & 12 \\
\hline Professionalism & 42.53 & 19.54 & 8.05 & 4.71 & 9.64 & 7.32 & 3.80 & 2.67 & 1.37 & 1.39 & 0.00 & 0.00 \\
\hline Eloquence & 0.00 & 6.90 & 1.15 & 5.88 & 4.82 & 3.66 & 5.06 & 9.33 & 12.33 & 18.06 & 18.06 & 25.00 \\
\hline Communicativeness & 6.90 & 12.64 & 16.09 & 8.24 & 10.84 & 17.07 & 8.86 & 4.00 & 5.48 & 4.17 & 4.17 & 2.78 \\
\hline Dexterity & 4.60 & 2.30 & 5.75 & 8.24 & 6.02 & 12.20 & 11.39 & 10.67 & 8.22 & 12.50 & 8.33 & 5.56 \\
\hline Speed & 11.49 & 8.05 & 10.34 & 18.82 & 15.66 & 9.76 & 8.86 & 8.00 & 2.74 & 6.94 & 0.00 & 2.78 \\
\hline Responsibility & 4.60 & 9.20 & 10.34 & 11.76 & 9.64 & 12.20 & 7.59 & 8.00 & 10.96 & 8.33 & 4.17 & 2.78 \\
\hline Organizational stage & 1.15 & 4.60 & 11.49 & 7.06 & 12.05 & 10.98 & 12.66 & 16.00 & 6.85 & 5.56 & 5.56 & 1.39 \\
\hline Sense for the teamwork & 3.45 & 1.15 & 3.45 & 3.53 & 2.41 & 3.66 & 11.39 & 6.67 & 10.96 & 12.50 & 16.67 & 26.39 \\
\hline Conciseness & 0.00 & 1.15 & 0.00 & 0.00 & 2.41 & 4.88 & 5.06 & 8.00 & 16.44 & 9.72 & 31.94 & 20.83 \\
\hline Finality - the ability to complete solutions & 2.30 & 12.64 & 10.34 & 14.12 & 6.02 & 7.32 & 8.86 & 10.67 & 8.22 & 8.33 & 2.78 & 4.17 \\
\hline Quality appreciation of customer requirements & 6.90 & 9.20 & 12.64 & 9.41 & 15.66 & 7.32 & 10.13 & 9.33 & 6.85 & 4.17 & 5.56 & 2.78 \\
\hline $\begin{array}{l}\text { The ability of complete and quality } \\
\text { assessment of customer requirements }\end{array}$ & 16.09 & 12.64 & 10.34 & 8.24 & 4.82 & 3.66 & 6.33 & 6.67 & 9.59 & 8.33 & 2.78 & 5.56 \\
\hline
\end{tabular}

Source: Authors' estimations. 


\section{Conclusion}

The institution of a Help Desk as a position in the business and information system is a place where the user and the system come face-to-face. At the same time, this interface is a form of communication between the user and the system and functions in order to meet the customer's needs. It is not necessary that it provide a software solution, but this is the most common form of tool used to solve a user's possible problems. If it is application software, then it is also the main source of problems. Specifically, the service provider assumes that the user has certain IT skills and knowledge in communication via the Help Desk. The second assumption is that there are infrastructure opportunities for the realization of the communication and implementation of such services.

Computer solutions and the method of organizing the database remains encapsulated on the side of the service provider, which can also be a source of problems. On the other hand, such encapsulation completely dehumanizes communication.

The research performed aimed to detect possible problems in this communication. We examined the views of stakeholders in order to determine their satisfaction with the quality of services provided. Therefore, the paper has moved away from the computer framework and thorough elaboration of information.

The study does have a hidden exclusivity. The majority of respondents are senior students who study computer science at university and polytechnic schools. That part of the population is in a position to assess both roles - of users and service providers.

A list of attributes offered, especially in the 16th question, is not necessarily closed and can serve as a basis for future research. Also, the questions and offered attributes can be used for further research and additional in-depth statistical analysis. The paper relied only on descriptive statistics for the fact that the Help Desk is usually tied to specific business and information systems. For this reason, the survey covered areas of wider public importance for respondents/users.

Further studies may consider all of the above, abstracted, and concretized activities of the system, e.g. education, production etc., and thus cover the phenomenon of the Help Desk in more depth and from all the mentioned aspects.

\section{References}

Beisse, F. (2014). A Guide to Computer User Support for Help Desk and Support Specialists. Boston, Massachusetts, United States: Cengage Learning.

Bruton, N. (2002). How to Manage the IT Help Desk (Computer Week). London: Routledge.

Czegel, B. (1998). Help Desk Practitioner's Handbook. London: Wiley and Sons.

Eckel, B. (2006). Thinking in Java, 4th Edition. London: Prentice Hall.

Erl, T. (2005). Service-Oriented Architecture (SOA): Concepts, Technology, and Design. Upper Saddle River, New Jersey, United States: Prentice Hall. 
Erl, T. (2013). Cloud Computing: Concepts, Technology \& Architecture. Upper Saddle River, New Jersey, United States: Prentice Hall.

Help Desk Service Level Expectations. (n.d.). Revised: 12/04/2015. Accessed April 1, 2017. Retrieved from goo.gl/tca8fu.

Help Desk Best Practices. (n.d.). Accessed April 1, 2017. Retrieved from goo.gl/2Sbp1G.

Guide to SaaS Help Desk Solutions: 6 Requirements. (2011, April). Accessed April 1, 2017. Retrieved from goo.gl/67S31C.

James, S. (2016). IT Help Desk: Your Blueprint To Service Success, Mastering User Support \& Troubleshooting Like A Genius. CreateSpace Independent Publishing Platform.

Jeong, Ch. H. (2007). Fundamental of Development Administration. Selangor: Scholar Press.

OECD. (n.d.). Public Governance and Territorial Development Directorate Recommendation of the Council on Digital Government Strategies (Adopted by the OECD Council on 15 July 2014). Accessed April 10, 2016. Retrieved from goo.gl/ jLPnX3.

Mohr, J. L. (2003). The Help Desk Audit: Blueprint for Success Spiral-bound. I.T. Gap Press.

Novell®. (2009). Novell. Open Workgroup Suite Small Business Edition Helpdesk. Retrieved from goo.gl/7efDDN.

Rumburg, J., Zbikowski, E. (n.d.). How Does YOUR Service Desk Stack Up? The Seven Most Important Performance Indicators for the Service Desk. Accessed April 1, 2017. Retrieved from goo.gl/T5EMpW.

Shannon, C. E., Weaver, W. (1963). The Mathematical Theory of Communication. Champaign, IL: University of Illinois Press.

Wiese, B. (2017). Service Level Agreement (SLA). Independently Published (In German). 
